\title{
NEW FEATURES OF THE NATO CENTRES OF EXCELLENCE IN SUPPORT OF THE NORTH-ATLANTIC ALLIANCE TRANSFORMATION
}

\author{
Eduard SIMION, Alexandru KIS \\ NATO HUMINT Centre of Excellence, Oradea, Romania \\ alexandru.kis@natohcoe.org
}

\begin{abstract}
The number of NATO Centres of Excellence (COES) has constantly increased, covering further disciplines of interest for NATO capability development. Meanwhile, the involvement of participating nations in COEs augmented, as a proof of the added value COEs bring not only to NATO, but to the involved nations - key stakeholders of these ventures - as well. The quantitative aspect of the NATO COEs network status is complemented by qualitative dimensions describing the current and projected work of the Centres. Their activity aims at top contribution within the four pillars their programs of work cover - doctrine development and standardization, concept development and experimentation, education and training, or lessons learned management. In this respect, this paper further investigates recent developments on the COEs network's stage, where acquiring Quality Assurance seal and accreditation as Education and Training Facilities for NATO, or even more achieving the Department Head status for the disciplines they cover, is a real mark of excellence and an indicator of successful entrepreneurship.
\end{abstract}

Keywords: Centres of Excellence, education and training, custodian, department head, lessons learned

\section{Introduction}

In his Annual Report for 2015, the NATO Secretary General - Jens Stoltenberg - reviewed NATO's three core tasks - collective defence, crisis management and cooperative security under the light of recent security developments.

Observing a dramatic slowing of cuts to defence spending among most of the Allies (as agreed at the Wales Summit) after years of a severely decreasing trend, Mr. Stoltenberg praised what he called "the greatest strengthening of NATO's collective defence since the Cold War" throughout increased presence in the Eastern part of the Alliance [2], raise of NATO Response Force capacities and operationalization of the Very High Readiness Force, intensified exercising and training, improved capabilities to combat hybrid warfare, enhanced intelligence and early warning, improved cyber defence and significant progress with NATO's ballistic missile defence system.

This complex scenario, where unpredictable evolutions may lead to a large array of threats against Nations, entails equal response from NATO; adaptation to this environment requires a diversified spectrum of capabilities, to which NATO Centres of Excellence (COEs) bring invaluable contribution.

The following chapters will seek to capture recent evolution within NATO COEs network and to outline the importance of a series of achievements that position COEs at the spearhead of NATO 
capabilities transformation efforts.

\section{NATO Centres of Excellence network - emerging functional features}

COEs are NATO accredited International Military Organizations (IMOs) with primary aim to support the Alliance's transformation requirements. COEs offer recognized expertise and experience, while avoiding the duplication of assets, resources and capabilities already present within the NATO Command Structure (NCS). Although not part of the NCS, COEs are part of the wider Transformation Network supporting NATO Command Arrangements, under ACT coordination (through Transformation Network Branch).

COEs are a versatile outreach tool for NATO, actively seeking involvement and more relevant contribution within the transformation pillars - doctrine and standards development, concepts development and experimentation, education and training, lessons learned/ best practices (LL/BP) and analysis.

Observing at a first glance the strategic importance of the connection between COEs and relevant NATO Working Groups, we would briefly mark a series of top achievements of COEs in their multilateral endeavours, such as custodianship of NATO standards, leading roles of the LL/BP Communities of Interest, acquiring Quality Assurance seal and accreditation as Education and Training Facilities for NATO, or even more attaining the Department Head status for the disciplines they cover, as mark of excellence and an indicator of successful entrepreneurship.

\section{Custodianship role in COEs` portfolio}

As all the 23 accredited COEs are involved in developing NATO doctrines or other Allied Publications (covering more than $80 \%$ of Allied Joint Doctrine Architecture - level 1 and level 2 publications [3]), the major achievement in this field of activity is covering the custodianship tasks for the NATO standards. So far, $8 \mathrm{COEs}$ are custodians for doctrines in their area of expertise (CIED, CIMIC, EOD, HUMINT, JAPCC, JCBRN, MILENG, MILMED), and one in his way to take over this responsibility (CCD).

The NATO Standards' Custodians work within the Alliance standardization framework, being connected to a broad array of actors and following complex processes in their specific activity.

The NATO Standardization Organization charter defines standardization as development and implementation of concepts, doctrines and procedures in order to reach and maintain the stage of compatibility, interchangeability or commonality necessary to achieve a certain level of interoperability, or optimization of the resources in the operational, technical, and administration domains. [4]

In NATO, the Committee for Standardization (CS) is the senior NATO committee for Alliance standardization, composed primarily of representatives from all NATO countries. Operating under the authority of the North Atlantic Council (NAC), it issues policy and guidance for all NATO standardization activities [5].

Further, the entity responsible for initiation, harmonization, coordination and support of the standardization activity under the authority of the CS is the NATO Standardization Office (NSO). The NSO responsibilities are also directed to support approximately 120 working fora (each of them designed for a specific domain/specialty) attended by some 6,000 subject-matter experts from NATO and partner nations [6]. In this way, the output standardization documents - gathers elements of military theory, historical experience, or operational practice of 28 Member Nations, to which the contribution of Partner Nations is more and more relevant.

For COEs, as doctrine [7] (or other standards) custodians, the main work is directed towards maintaining the relevance 
and actuality of their documents by periodical reviews; the relevant input in this spectrum are counted as "top-down" and "bottom-up" requirements for change [8].

For customers, the NATO Standardization Documents Database (NSDD) [9] provides selectively - based on classification level - a consolidated storage of all NATO standardization documents $(1,200$ NATO standards are available for download to registered users; in addition, there are some 8,000 other standardizationrelated documents available[10]) and their related information, including national ratification data. A similar approach is done for NATO terminology, which is stored and managed by the NATO Terminology Database.

\section{The Quality Assurance stance in COEs accreditation as NATO Education and Training Facilities}

NATO conducts education and training activities in order to attain three main objectives: to increase the effectiveness of NATO-led multinational forces and their interoperability, assist partner countries in their reform efforts, and support to the international peace and stability efforts in crisis-hit areas [11].

The NATO education and training functions have significantly increased nowadays, registering an impressive expansion in matters of collaboration and cooperation; qualitatively, it has been reinforced through the creation of the ACT [12] after the Prague Summit, in 2002, and the adoption of international standards in matter. The introduction of new bodies and initiatives - such as COEs, Partnership Training and Education Centres, or Partnership for Peace Consortium of Defence Academies and Security Studies Institutes has also demonstrated the resolve to reinforce education and training activities for the Organization.

All the entities attached to ACT and clustered into the Transformation Network fulfil education and training functions. In this spectrum, COEs' effectiveness for NATO education and training system is double checked in terms of quality - first, by accreditation of COEs as IMOs (based on a comprehensive set of qualitative and quantitative criteria that a COE must fulfil), and second, through the COEs' application as NATO Education and Training Facilities (ETFs), where they have to proceed for supplementary accreditation, from quality assurance perspective - derived from the EU standards for higher education institutions.

A Quality Assurance (QA) system supports the overall management of an institution, increasing its autonomy, contributing to sustainability, optimization of the use of resources, improving communication and relationship within working networks, and finally enhancing the output to fit the customers' requirements.

QA in higher education achieved its modern features trough the Bologna process, which evolved from strengthening the competitiveness and attractiveness of the European higher education and fostering student mobility and employability to a broader agenda, linking the undergraduate/ postgraduate degree structure (including the concept of qualifications frameworks) to the concept of social dimension of higher education [13].

Meanwhile, adoption of a Quality Management System (QMS) [14] in NATO subsidizes alignment with the required standards, the development of effective, efficient and affordable education and training solutions, and the quality of the training opportunities.

Implementation of a QA process ensures that NATO's standards, in line with international Educational Standards, expressed in Educational Goals and derived Educational Standards are met. In this respect, NATO applied in 2012 for the European Association for Quality Assurance in Higher Education (ENQA). Adoption of the ENQA norms and QA 
methodology, doubled by permanent monitoring and external certification of quality, ensures high-quality references and enhance mutual trust between high education institutions from different countries.

Further on, the NATO Quality Standards are found in the traits of: leadership and management, education and training, and contribution to NATO.

\section{Department Head appointment for COEs}

The NATO education and training structure and functions have been recently consolidated and optimized into the Bi-SC 75-2 Education and Training Directive (E\&TD) (October 2013) [15] and the new NATO Education, Training, Exercises, and Evaluation (ETEE) Policy (MC 0458/3 from September 2014), where the Department Head (DH) attributes are detailed.

A developed set of roles for $\mathrm{DH}$ is equally included in the memoranda signed by the appointed DHs (some of them COEs) with the HQ SACT representative (the JFT head) [16].

\section{Lessons Learned/ Best Practices Communities of Interest}

The purpose of the NATO Lessons Learned/ Best Practices capability is to learn efficiently from experience and to provide validated justifications for amending the present way of action in order to improve performance for (subsequent) operations.

Although the Joint Analysis and Lessons Learned Centre (JALLC) is NATO's institution designed to perform analysis of operations, training, exercises and experiments, based on the requirements generated by both NATO strategic commands [17], it is almost impossible for the JALLC to cover with proper expertise all functional areas. Therefore, it works closely with stakeholders and subject matter experts that support all stages of its projects.

As COEs impetuously emerged as hubs of expertise in NATO, most of them using the LL/BP process to facilitate the capability development based on feedback, it was a logical option to make use of this valuable resource and to connect them with the overarching NATO Lessons Learned system directed by JALLC.

Based on existing capabilities and proven expertise, SACT entitles selected COEs as out of theatre coordinators of their functional area Lessons Learned. In support of this, an area dedicated to each specific Community of Interest (COI) is created in the NATO Lessons Learned Portal (NLLP) [18], where Nations/NATO bodies share within COIs LL/BP and proceed with further analysis and proposals for remedial actions.

There is a total number of $13 \mathrm{COIs}$ hosted on classified and/or unclassified NATO networks [19], from which 3 COEs [20] are in charge for management and coordination for their functional areas.

\section{Conclusions}

Centres of Excellence - one of the best examples of Smart Defence projects in NATO - are at the spearhead of NATO transformation efforts, having a lead role in most of the supporting pillars.

Beside the NATO requirements feeding their Programmes of Work, the establishment and coordinated work in each domain within their Communities of Interest - most often NATO Working Groups or Coordination Panels - is the necessary connection between practitioners' work and the national experts giving weight to any decision on the way to follow. Ensuring the chairmanship of such fora by COEs' top leadership (as we may count some cases in NATO) is, first of all, a recognition of merit, and second, an extraordinary opportunity to act in a coordinated manner toward the established objective. Therefore, this is a first strong point in a COE's activity, counted for 
policy, planning and direction.

As most of the COEs are involved in supporting standardization, custodianship of the domain's doctrine (and other standards) is the secondly counted on the achievements' board. The concept development and experimentation dimension, which is present in the activity of all COEs, in different forms, is the hardest to be quantified, as all outcomes bear value and provide contribution to the discipline advance.

Education and training are key agents for transformation; in this realm, the principal role of COEs is to provide highquality education and training to the EuroAtlantic community. In this respect, institutional accreditation and the QA seal are of paramount importance. A further step is the appointment as $\mathrm{DH}$ for an education and training (sub)discipline, which offers enhanced oversight on the discipline E\&T. In education and training management, this is the top position a COE can fulfil.

A positive LL mindset across an organization is extremely important, governing the success of real learning, sustained improvement, and profitable knowledge-sharing among the Allies. The LL/BP process closes the feedback cycle of providing actualized and adapted knowledge (in doctrines, procedures, etc.), which is further on transferred to customers within the education and training events. The major involvement of COEs in this domain is to support NATO LL/BP collection efforts in a specific functional area and assure subject matter expert support in the analysis phase; coordination of a specific LL/BP Community of Interest comes as a natural evolution and is counted as an institutional major success.

Figure 1 graphically depicts the level of COEs' achievements/ involvements in the transformation support spectrum [21].
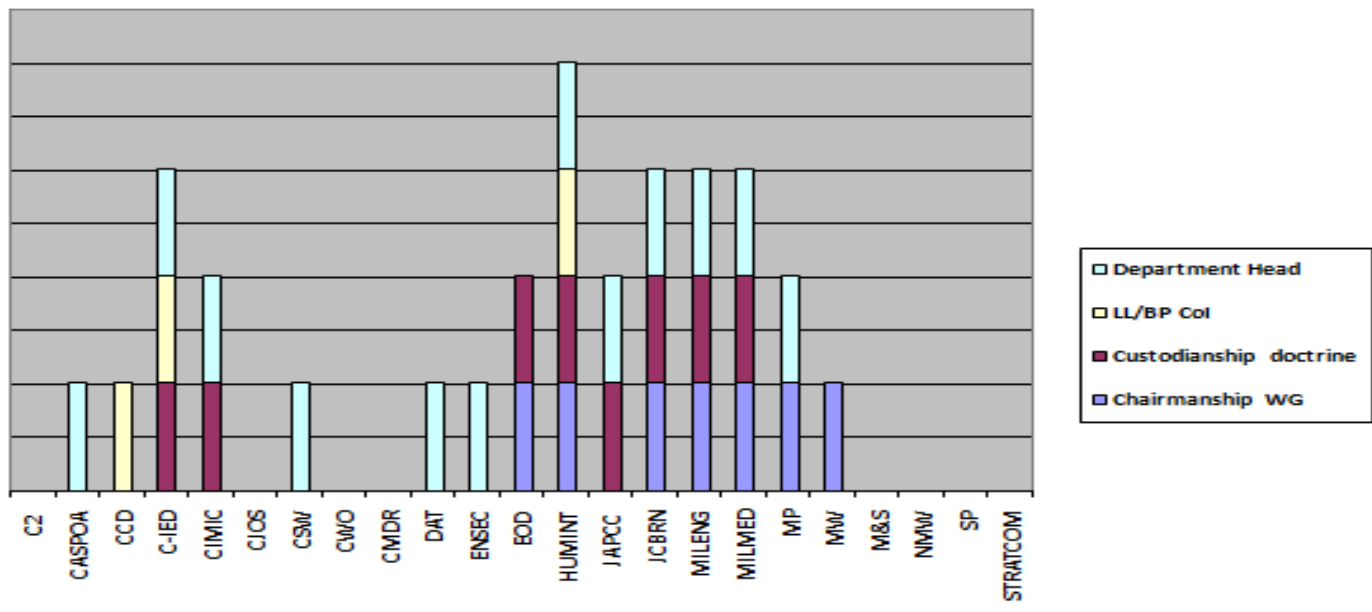

Figure 1 Accredited COEs `levels of performance in support of NATO transformation pillars

From the chart above, we can acknowledge significant differences among COEs; while praising performance, we recognize a series of factors behind the scene, which can limit a COE's performance:

- internal factors: limited functional area covered by the COE Concept; the leadership vision decupled from a certain development direction; a functional management not connected to NATO trends; missing expertise/ training/ outsourcing; lack of resources; lack of feedback (LL/BP); prioritization; institutional resilience;

- external factors: national political (lack of) willingness; absence of NATO Policy for a certain discipline; focus on an emergent discipline, not consolidated; absence of NATO dedicated discussion fora (working groups, panels); deficient networking; strategic prioritization.

However, strong leadership support and commitment, collaboration with 
experienced partners, verified internal processes and - above everything institutional motivation are part of the performance menu that has to be applied in any COE.

From a personal perspective, the top quality position of HCOE - the only NATO Centre of Excellence hosted by Romania - is devoting years of steady efforts in support of continuous transformation and modernization of NATO's forces and capabilities, honouring the excellent work of a proud group of experts from nine nations: Romania, Czech Republic, Greece, Hungary, Poland, Slovakia, Slovenia, Turkey, and the USA.

\section{References}

[1] Disclaimer: This paper expresses the views, interpretations, and independent position of the authors. It should not be regarded as an official document, nor expressing formal opinions or policies, of NATO or the HCOE.

[2] It is expected at the next NATO Summit in Warsaw, in July 2016, to decide on the balance between a forward presence and NATO ability to reinforce.

[3] As of ACT - Transformation Network Branch figures.

[4] C-M(2009)0056 NATO Standardization Organisation (NSO) Charter.

[5] http://www.nato.int/cps/en/natohq/topics_69277.htm

[6] Akşit, Cihangir, Smart standardization: a historical and contemporary success at NATO, 2014 in http://www.nato.int/cps/en/natohq/topics_69269.htm.

[7] As of Allied Joint Doctrine AJP-01, doctrine is defined as "fundamental principles by which military forces guide their actions in support of objectives. It is authoritative, but requires judgment in application". The principal purpose of doctrine is to provide the framework of guidance for the conduct of operations, and is about how those operations should be directed. If the doctrine describes how a force operates, the policy comes to explain why they do what they do. A doctrine is meant to be dynamic and constantly reviewed for relevance.

[8] Kis, Alexandru, Standardizarea disciplinei HUMINT in NATO, proceedings of the conference "Tehnologiile mileniului al III-lea şi viitorul activităţii de informaţii", $3^{\text {rd }}$ edition, Bucharest, 2013, sectiunea 2, p. 7.

[9] http://nso.nato.int/nso/nsdd/_CommonList.html?runQ=no

[10] Akşit, Cihangir, Idem.

[11] http://www.nato.int/cps/en/natohq/topics_49206.htm

[12] ACT holds lead responsibility for NATO and PfP joint education, individual training, and associated policy and doctrine development as well as for directing NATO schools. Since July 2012, ACT has also been given the responsibility of managing collective training and exercises based on Allied Command Operations' requirements.

[13] http://www.ehea.info/article-details.aspx?ArticleId=3

[14] The QMS standards are oriented toward: policy and procedures; staff/ instructors development; information systems and knowledge management; public information; definition and delivery of instruction; student assessment; learning resources and student support.

[15] Within the hierarchy of NATO's E\&T directives, Bi-SC 75-2 subordinates: Bi-SC 75-7 Education and Individual Training Directive, Bi-SC 75-3 Collective Training and Exercise Directive, and Bi-SC 80-6 Lessons Learned Directive.

[16] Simion, Eduard; Kis, Alexandru, The NATO HUMINT Centre of Excellence as Department Head for Human Intelligence education and training in NATO, proceedings of the 10th Scientific Conference "Defense Resources Management in the $21^{\text {st }}$ Century", 
National Defense University „Carol I”, Regional Department of Defense Resources Management Studies, 2015, pp 92-100.

[17] JALLC, The NATO Lessons Learned Handbook, Third Edition, February 2016.

[18] https://nllp.jallc.nato.int/Pages/default.aspx

[19] JALLC, The JALLC Explorer, Volume 6 Issue 1, April 2015, Lisbon, in http://www.jallc.nato.int/products/explorer.asp\#jev6i1.

[20] https://nllp.jallc.nato.int/cmnt/Pages/Communities.aspx

[21] Chart data is based on available information retrieved from COEs' web pages, Transformation Network Branch, and JALLC. 